\title{
Teaching the Global Impact of Computing
}

\author{
Jennifer Rosato \\ College of St. Scholastica \\ 1200 Kenwood Ave. \\ Duluth, MN 55811 \\ +1218-723-6152 \\ jrosato@css.edu \\ Bradley Beth \\ University of Texas at Austin \\ 1 University Station \\ Austin, TX 78712 \\ +1 802-673-8309 \\ bradleybeth@utexas.edu
}

\author{
Nigamanth Sridhar \\ Cleveland State University \\ 2121 Euclid Ave FH 332 \\ Cleveland $\mathrm{OH} 44115$ \\ +1 216-687-5341 \\ n.sridhar1@csuohio.edu
}

\author{
Jeff Gray (moderator) \\ University of Alabama \\ Box 870290 \\ Tuscaloosa AL 35487 \\ +1 205-348-2847 \\ gray@cs.ua.edu
}

\begin{abstract}
Keywords
AP Computer Science Principles; Global Impact of Computing; interdisciplinary teaching methods
\end{abstract}

\section{SUMMARY}

Connecting computing with its social contexts and implications can be a powerful way to motivate a wide variety of students to learn about computer science. In designing the new AP Computer Science Principles course and exam [1], the College Board included "Global Impact" as one of the seven major organizing principles ("Big Ideas"). Many teachers are excited to see this "missing piece" added to computer science education — but exactly because it's innovative, it can be difficult to know how to teach it!

This panel brings together leading CS educators who are building curriculum and professional development materials for AP CSP, and collaborating on an NSF-sponsored project to build an integrated Global Impact resource. Panelists will discuss how they incorporate the impact of computing -- including its benefits and its potential downsides -- into curricula (CSP and otherwise). The discussion will cover varied perspectives on how to cover this unusual topic, including relevant techniques from social studies and language arts (yes, reading and writing in a CS class!), along with project-based and peer-instruction approaches, effective hooks, and ideas about integrating impact into the nitty-gritty of programming assignments.

\section{PANEL POSITION STATEMENTS}

The following are the position statements of each panelist.

\subsection{Jennifer Rosato}

Jennifer Rosato is a project lead for the Mobile Computer Science Principles (CSP) project. Mobile CSP is centered around the premise that students are highly motivated to learn computer science when they are able to build socially useful apps - apps that make a difference for their community, whether that be family, friends, school, church, town, or other community aspects. This aspect of Mobile CSP ties into the CSP Big Idea of Global Impact. Students build apps through guided tutorials, miniprojects, and a practice performance task that try to emphasize their usefulness to society. For example, one guided tutorial is No

Permission to make digital or hard copies of part or all of this work for personal or classroom use is granted without fee provided that copies are not made or distributed for profit or commercial advantage and that copies bear this notice and the full citation on the first page. Copyrights for third-party components of this work must be honored. For all other uses, contact the Owner/Author. Copyright is held by the owner/author(s).

SIGCSE '17, March 08-11, 2017, Seattle, WA, USA.

ACM 978-1-4503-4698-6/17/03.

http://dx.doi.org/10.1145/3017680.3017696.
Texting While Driving, which includes thinking about how cell phones have impacted driving and how the app can be used to address the problem of distracted driving. Another pedagogical component Mobile CSP has worked to address is providing professional development around reading in the content area, as many impact lessons (in a variety of CSP curricula) are based on reading about computer science. Teachers may not have received training on how to teach and support reading activities, and so feel unprepared to teach readings from the Blown to Bits book or other sources. Strategies to use in pre-reading, during reading, and postreading activities will be shared along with common pitfalls to avoid.

\subsection{Bradley Beth}

Bradley Beth is Curriculum Specialist for the UTeach Computer Science Principles course. UTeach CSP is a College Board endorsed curriculum aligned to the AP Computer Science Principles framework that focuses on delivering a broad perspective on computer science through Project-Based Learning (PBL) and equitable, creative activities. As part of the open-ended nature of the course, students are expected to document solutions with discussion of tradeoffs and context. Impact is a primary focus of the curriculum - whether global, local, or personal - and drives much of instruction. Students investigate computing in the contexts of assistive devices, application to art and media, politics, and more. Student projects include applying computational techniques to a novel dataset to tell a story and extrapolating known technologies to prototype a computational innovation. Professional learning opportunities for the curriculum are concentrated on the teaching of computational thinking through open-ended PBL, rather than focusing on programming.

\subsection{Nigamanth Sridhar}

Nigamanth Sridhar is a Professor in the Department of Electrical Engineering and Computer Science at Cleveland State University. Since 2014, he has been the project lead for the Computing in Secondary Schools (CISS) project, which has prepared 50 teachers from all across Ohio on a CS Principles curriculum. The CSP curriculum used in CISS has been adapted from the ComPASS project from the University of California at San Diego. In the ComPASS curriculum, students build animated worlds using the Alice programming language. Over the duration of the course, students learn the fundamentals of object-based programming, abstraction, and algorithm development. The particular contributions to the ComPASS curriculum that CISS has made center on the Global Impact and Internet big ideas, incorporating a number of computing innovations and pedagogical methods. The CISS/ComPASS course is taught using the peer instruction methodology, which heavily depends on students participating in discussions in the classroom environment, based on readings and assignments completed prior to the class. The course also uses in-class simulations as a 
pedagogical construct to help students explore the global impact of computing innovations. For example, students use role-play to explore the impact of Net Neutrality legislation and regulations on society's access to and use of the Internet.

\subsection{Jeff Gray (Moderator)}

Jeff Gray is a Professor in the Department of Computer Science at the University of Alabama. Since 2011, he has been a Pilot Instructor for the College Board's new AP CS Principles course. $\mathrm{He}$ also was the project lead for CS4Alabama, an NSF CS10k project that trained 50 teachers from Alabama on a CS Principles curriculum, which was later adapted to a MOOC through support from Google CS4HS. Presently, Jeff is a member of the NSF CS10k project that will help to bring Exploring Computer Science to the Black Belt region of Alabama, which includes two of the top-ten most impoverished counties in the US. From his experience, the diverse demographics of Alabama present unique opportunities to introduce the impact of computing in different contexts. Jeff will briefly share his project experiences, but mainly serve as a moderator for the discussion among the panelists.

\section{ACKNOWLEDGEMENTS}

The panelists are supported in part by the following NSF projects (1240944, 1339270, 1543014, 1441009, 1138506). The combined Teach Global Impact resource is supported by NSF grant \#1637601.

\section{REFERENCES}

[1] The College Board. 2016. AP Course and Exam Description: AP Computer Science Principles, Including the Curriculum Framework. https://securemedia.collegeboard.org/digitalServices/pdf/ap/ap-computerscience-principles-course-and-exam-description.pdf 